\title{
Evacuating a First Nation Due to Wildfire Smoke: The Case of Dene Tha' First Nation
}

\author{
Kyla D. Mottershead ${ }^{1}$ Tara K. McGee ${ }^{1} \cdot$ Amy Christianson $^{2}$
}

Published online: 12 June 2020

(C) The Author(s) 2020

\begin{abstract}
Almost every year, First Nations are evacuated in Canada because of wildfire proximity and smoke. Dynamics of wildfires, and remote locations, unique sociocultural characteristics, and limited emergency management resources present challenges for evacuation organizers and residents. This study explores how Dene Tha' First Nation evacuated their Taché community in July 2012 due to wildfire smoke and how the evacuation process affected evacuees. Interviews were completed with 31 evacuation organizers and residents to examine the factors that helped and hindered the evacuation process. Lack of information about the nearby wildfire, smoke, and evacuation of the nearby small community of Zama City, combined with a generic evacuation plan, delayed and posed challenges during the evacuation of this Dene Tha' community. Strong leadership and its role in community organizing, keeping families together, providing the social support they needed, and using familiar host communities, demonstrated and contributed to the community's resilience during the evacuation. Measures to improve evacuations and emergency management in the community and other First Nations in Canada are identified and discussed.
\end{abstract}

Keywords Community resilience - Evacuation planning · First Nations · Indigenous peoples · Wildfire smoke

Tara K. McGee

tmcgee@ualberta.ca

1 Department of Earth and Atmospheric Sciences, University of Alberta, Edmonton, AB T6G 2E3, Canada

2 Canadian Forest Service, Northern Forestry Centre, Edmonton, AB T6H 3S5, Canada

\section{Introduction}

In most countries, wildfire management agencies recommend evacuation when people are at risk. Although evacuation is used to protect health and safety, the process itself is one of the most disruptive consequences of wildfire (Taylor et al. 2005; Cohn et al. 2006; Paveglio et al. 2008; Asfaw et al. 2018, 2019; Christianson et al. 2019; McGee 2019). How an evacuation is carried out influences how evacuees are affected. Wildfire evacuations are an inherently disordering experience because they frequently occur with little or no warning and at any time of the day or night (Taylor et al. 2005; Cohn et al. 2006; McCool et al. 2006; Paveglio et al. 2008; Christianson et al. 2019; McGee 2019). In addition, evacuees can experience a disruption in their normal routines because evacuations can occur more than once in a fire season, with periods of displacement lasting anywhere from a few days to several months, depending on the damage caused by the fire (Cohn et al. 2006; Hodgson 2007; Tally et al. 2012; Asfaw et al. 2018, 2019; Christianson et al. 2019).

In Canada, a high proportion of wildfire evacuations involve Indigenous peoples. Many First Nation reserves are located in forests that frequently experience wildfire (Wotton and Stocks 2006), and 60\% of First Nation reserves are located within or intersect the wildland urban interface (McGee et al. 2019). First Nations are also more likely to be evacuated due to wildfires. Beverly and Bothwell (2011) found that although comprising $4.9 \%$ of the population, almost $1 / 3$ of wildfire evacuations between 1980 and 2007 involved Indigenous peoples. When a wildfire threatens a First Nation, the initial response rests with the First Nation Chief who uses available information, observations, and knowledge of their community to decide whether to order an evacuation under time-sensitive 
conditions. Depending on the information from provincial and federal government agencies and numerous logistical factors, an evacuation may only involve community members at high risk from wildfire smoke or it may involve the entire community. If a mandatory evacuation is ordered, the First Nation band council and other community members, federal government departments, provincial government departments, police, nongovernment organizations, and host communities may also be involved in the evacuation.

First Nations may have a low level of emergency preparedness, which can limit their capacity to respond to wildfires (Epp et al. 1998; Office of the Auditor General of Canada 2013; Scharbach 2014; Asfaw et al. 2018; Clark 2018). In addition, the ongoing effects of colonialism's legacy, which have caused individual, family, and community-wide challenges, may make it more difficult for First Nations to cope with the disruptive nature of wildfire evacuations (Furgal and Seguin 2006; Alfred 2009; Coulthard 2014). Despite the challenges they face, many Indigenous people and communities have or are beginning to recover from intergenerational trauma (LaFromboise et al. 2006), highlighting their resilience. While the vulnerability of First Nations to hazard events and emergencies has been identified by previous studies (Epp et al. 1998; Office of the Auditor General of Canada 2013; Scharbach 2014; Clark 2018), limited research has examined how resilience is operationalized or demonstrated by First Nations during an evacuation. Recently, Clark (2018) examined the resilience of Indigenous communities during the 2016 Fort McMurray fire; and Yumagulova et al. (2019) examined several case studies of Indigenous communities' resilience during a wildfire and other hazard events.

Research on community level resilience to hazard events has examined how communities avoid, reduce, or cope with the damages caused by disasters, and how they recover with minimal social disruption (Buckle et al. 2000; Manyena 2006; Tierney and Bruneau 2007). Investigations have focused on identifying the factors, processes, and contexts that influence resilience at the community level in the short and long term to provide direction for better interventions before, during, and following future hazard events (Paton et al. 2000; Kulig et al. 2008, 2011, 2012; Twigg 2009; Cox and Perry 2011; Krishnaswamy et al. 2012; Townshend et al. 2014). Common factors that have been found to influence community resilience include social networks and community within those networks; social support and the sense of belonging it fosters; community leadership and its role in community organizing; outlook on life such as the readiness to accept change and learning; and infrastructure and support services, particularly their role in facilitating the use of community strengths (Goldstein 2008; Davidson 2010; Levy et al. 2012; Berkes and Ross 2013; Townshend et al. 2014). In their Disaster Resilience of Place model, Cutter and colleagues (2008) identify adaptive resilience, including improvisation and social learning, which can occur following a hazard or disaster event. Improvisation includes unplanned impromptu actions that can help the recovery process. Social learning involves these impromptu actions being formalized so that they can be used to handle future events.

This study builds on this existing research by examining the evacuation of the Dene Tha' First Nation community of Taché (Meander River), Alberta, in July 2012. The objectives of this study are to:

- Explore how Dene Tha' First Nation evacuated their Taché community for 7 days in July 2012 due to wildfire smoke;

- Identify factors that helped and hindered the evacuation process; and

- Examine how the evacuation process affected evacuees.

The research was completed using social constructivist and postcolonial lenses, which acknowledge that there are multiple realities and ways of knowing, and uses the research process as a way of contributing to the self-determination and empowerment of "others" through methodologies that value their insights, knowledge, perspectives, experiences, and concerns (Howitt and Stevens 2010; Howitt et al. 2012).

\section{Dene Tha' First Nation and Taché}

The Dene Tha', which in the Dene Dháh language means the "people common to the territory," or "common peoples," are a First Nation people who live in northwestern Alberta (Goulet 1998). The declared Dene Tha' Traditional Territory covers the northwestern section of Alberta, the northeastern part of British Columbia, and the southern sections of the Northwest Territories (Campbell and Arctic Institute of North America 1997; Goulet 1998). In 1900, the Dene Tha' signed Treaty 8 and were allocated seven parcels of land as reserves. Today, many of the Dene Tha' inhabit three of the seven reserves located in northwestern Alberta (Fig. 1). They support themselves through a combination of wage work, government subsidies, and traditional subsistence activities. The First Nation has a total registered population of 2971 members, with approximately 2000 people living on reserve in three communities: Bushe River adjacent to the towns of High Level, Taché, and Chateh. These Dene Tha' reserves in northwestern Alberta are located within Mackenzie County, a specialized municipality of just over $80,000 \mathrm{~km}^{2}$ in the northwest 


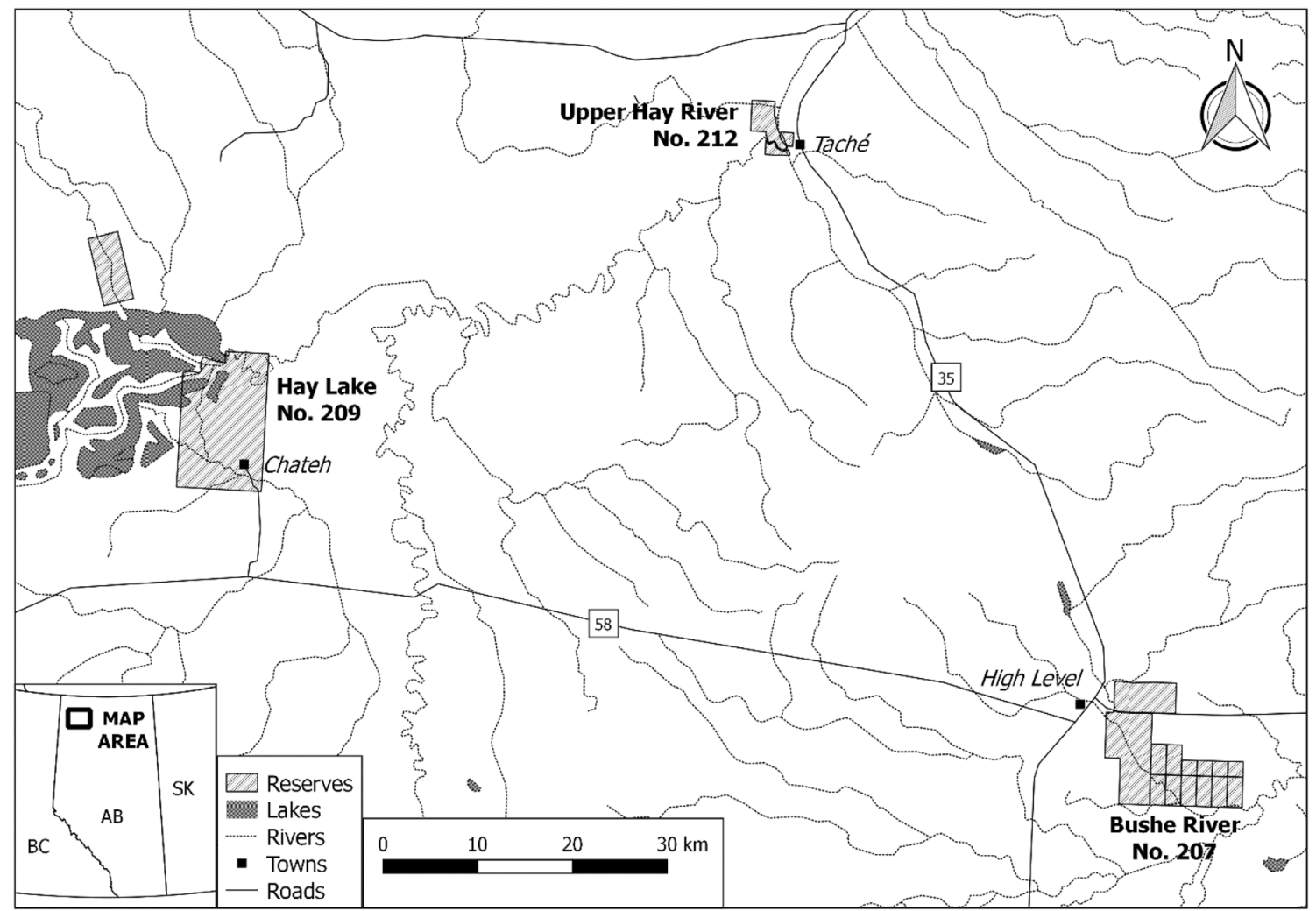

Fig. 1 Location of Bushe River, Chateh, and Taché reserves, Dene Tha' First Nation, Alberta, Canada

corner of Alberta. The county includes two small towns (High Level and Rainbow Lake), several hamlets (Fort Vermilion, La Crete, and Zama City), and four First Nations (Beaver First Nation, Tallcree First Nation, Little Red River Cree Nation, and Dene Tha' First Nation).

In the last census (2016), the median age of the Dene Tha' population was 28.5 years compared to 37.8 years for Alberta as a whole (Indigenous and Northern Affairs Canada 2019a). Current on-reserve facilities vary between the three communities but include First Nation offices, public works buildings, and schools. Despite ongoing extraction of natural resources such as oil, gas, and timber products from their traditional territory, Dene Tha' First Nation continues to suffer high levels of poverty and unemployment. For example, in 2016 the average total income for individuals was CAD 18,550, compared to CAD 62,778 for the province of Alberta (Indigenous and Northern Affairs Canada 2019b). Likewise, the unemployment rate of $33.3 \%$ was higher than the rate of $9.0 \%$ for Alberta as a whole (Indigenous and Northern Affairs Canada 2019c).

Taché is the smallest of the three occupied reserves of Dene Tha' First Nation. It is in the boreal forest, $75 \mathrm{~km}$ north of the town of High Level on the west side of Highway 35 . The community has a population of approximately 400 people. Many homes are occupied by several generations of family. The community has a band complex with community services such as counselling, social work, and a local radio station. It is also used for training workshops, band council meetings, and other community gatherings. The reserve also has a small volunteer fire department, a community health center, and a primary school (kindergarten to grade 9). Like other First Nation communities in Canada, Taché is subject to challenges associated with post-colonialism including poverty, high unemployment rates, low education attainment, social, and chronic health problems. Children must attend school in the town of High Level if they continue beyond grade 9 . Employment opportunities in Taché are scarce, with only a small number of residents employed in local services. Some residents work as seasonal wildland firefighters and others seek work in High Level and beyond. Some members take part in fishing, trapping, and hunting but fewer and fewer young people are participating in these traditional activities (Spyce 2009).

At the time of this study, Dene Tha' First Nation had a director of emergency management (DEM) who was responsible for all hazard-related emergencies in the three Dene Tha' First Nation reserves. This position is voluntary, and the incumbent fulfills the duties of the position in addition to the duties of their regular full-time employment. Since the DEM at the time of this study resided in 
Chateh (approximately $100 \mathrm{~km}$ away), Taché's volunteer fire chief is an unofficial assistant during evacuations and other emergencies. In addition to the day-to-day coordination and organization of logistics for evacuations and other procedures, the DEM is responsible for overseeing cost recuperation from evacuations and damage incurred to property and infrastructure following a hazard incident.

\section{Materials and Methods}

This research is part of the First Nations Wildfire Evacuation Partnership, which was established in 2013 because of concerns about the well-being of evacuees and the lack of research regarding the evacuation experiences of First Nations in Canada. The partnership involves First Nations in Alberta, Saskatchewan, and Ontario, along with federal and provincial agencies and other organizations that provide support during evacuations. During the development of the partnership, a partner agency in Alberta identified Dene Tha' as a First Nation that had been evacuated as a result of a wildfire. A band administrator for Dene Tha' First Nation was subsequently contacted to discuss the aims of the research and determine if they might be interested in participating. Following a meeting with Chief and Council, Dene Tha' First Nation agreed to participate in the research.

Ethics clearance was obtained from the University of Alberta, Human Research Ethics Board. The First Nations principles of ownership, control, access, and possession (OCAP) were followed, and this research was carried out in accordance with Chapter 9 of the TCPS2 Tri-Council Policy Statement: Ethical Conduct for Research involving Humans on research involving First Nations, Inuit, and Métis peoples of Canada (Government of Canada 2014). This study used a qualitative, community-based, case-study research approach. We met with Chief and Council in early 2014 to discuss the planned research and sought feedback on the research approach and process. They identified three local leaders who would form a community advisory committee to provide additional advice and assistance throughout the research project. Two residents of Taché were also hired as research assistants to help with data collection, analysis, and results dissemination. Steps taken to ensure the rigor of this study included purposeful sampling, persistent observation, triangulation of sources, member checking, an audit trail, and consideration of positionality throughout the research process (Baxter and Eyles 1997).

Fieldwork took place during two visits to Taché in June (3 weeks) and August (1 week) 2014. Semistructured interviews were the main data collection method. Participants were recruited using purposeful and snowball sampling (Bradshaw and Stratford 2010). During the first visit, participants were recruited by putting up posters around the community and through recommendations from employees working at the band office, health center, and school. Snowball sampling was also used to recruit additional participants whereby interview participants provided referrals to friends and family members. During the second fieldwork visit, the community research assistants helped to recruit participants by contacting community members and inviting them to participate. We recruited key contacts, who were involved in organizing the evacuation and evacuees and aimed to interview evacuees with a range of perspectives and experiences. In addition to the interviews, participant observation during fieldwork provided valuable information about the community context, which included Dene Tha' cultural traditions, historical issues, and current social and economic conditions. The interviews took place in a location convenient for participants. Before their interview commenced, participants read the project information sheet and signed the informed consent form. Participants were asked to describe their wildfire evacuation experiences from the time when they first heard about the fire, during the evacuation, their time in the host community, returning home after the evacuation, what helped or hindered the evacuation process, lasting effects of the evacuation, post-evacuation preparedness activities, and any recommendations for improving future evacuations. All interviews were audio recorded with the permission of participants. In total, 27 interviews were completed with 31 people. Participants included three key contacts who were involved in organizing the evacuation, one firefighter who was not evacuated, and 27 evacuees. Participants included 10 men and 21 women ranging from 20 to 73 years of age (Table 1). Interviews were conducted until theoretical saturation was achieved (Bradshaw and Stratford 2010).

Data analysis began between the two field visits and continued after data collection was completed and the interviews were professionally transcribed. NVivo software was used to assist with the data analysis process. First, the transcripts were coded for descriptive codes from relevant literature, the interview topics, and initial analysis.

Table 1 Participant characteristics

\begin{tabular}{llcc}
\hline Age groups & Men & Women & Total \\
\hline $20-29$ & 1 & 3 & 4 \\
$30-39$ & 0 & 3 & 3 \\
$40-49$ & 3 & 9 & 12 \\
$50-59$ & 2 & 3 & 5 \\
$60+$ & 3 & 4 & 7 \\
Total & 9 & 22 & 31 \\
\hline
\end{tabular}


Analytic codes were then applied to emergent thematic categories such as different experiences reported by participants during the various stages of the evacuation. At this stage in the analysis, the first author visited Dene Tha' First Nation to present the initial results during two presentations; one to the Chief and members of Council, and one to participants and other community members during an open house and via the community radio station. After the initial analysis and community consultation, the complex coding structure was revisited and relationships between categories were explored. The DEM and Chief of Dene Tha' First Nation reviewed and provided feedback on this manuscript.

\section{Results and Discussion}

This section presents the results of this study including a description of how the community was evacuated and the factors that helped and hindered the evacuation process.

\subsection{Evacuation of Taché}

Taché was evacuated because of the Lutose Complex fires that were ignited by lightning on 21 June 2012, and spread rapidly due to the unusually hot and dry conditions. The decision to evacuate was made within the changing dynamics of the wildfire and the need to protect the health and safety of residents. On 10 July 2012, the specialized county of Mackenzie County, which includes the Dene Tha' reserves, declared a state of emergency when fires threatened the hamlet of Zama City west of Taché. Residents from Zama City were directed to an evacuation reception center set up in the town of High Level. At the same time, strong northwesterly winds began blowing heavy smoke and ash into Taché, which made it difficult for residents to breathe and see.

A voluntary evacuation was ordered for those at high risk from smoke, including small children, infants, pregnant women, people with chronic respiratory problems, and elders. The evacuation order was spread through the community by word of mouth. This evacuation began at approximately 9:00 p.m. on $10 \mathrm{July,} \mathrm{and} \mathrm{continued} \mathrm{until}$ the next morning. Most residents chose to evacuate during the voluntary evacuation because they wanted to accompany family members at high risk from smoke or because they were told about the evacuation but did not realize that it was voluntary. Most participants recalled that they had 10-15 min to pack a bag and leave. Some residents left on their own if they had a vehicle, some received a ride from family or friends, and others took a charter bus organized by the band.
When the air quality deteriorated further, the Chief and DEM declared a state of emergency and called for a mandatory evacuation of remaining residents. One band employee and the volunteer fire chief stayed behind to patrol the community in case blowing ash or embers ignited a fire, provide security, feed animals that were left behind, and provide updates to evacuees through the local radio station, text messages, and social media.

A reception center for Taché evacuees was set up at the band complex in the Bushe River community and operated by band employees. However, most Taché evacuees, including the passengers on the charter bus, mistakenly went to the reception center in the town of High Level instead of the reception center in Bushe River. There was a delay in obtaining accommodation in High Level due to other logistical challenges such as the last-minute nature of the evacuation at night and the need to get band employees and volunteers in place to help with the process under short notice. Some Taché evacuees stayed with friends and family in High Level, but others had to spend the night on the floor of the evacuation center before being assigned motel rooms the next day. High Level is a town with a population of approximately 3000 people at the time of the evacuation, with approximately $25 \%$ of the population selfidentified as Aboriginal. Due to its small size, High Level has limited motel space, so when motels were filled, young single people were provided with tents in Bushe River. Some evacuees decided to leave the area and go camping.

Most families were kept together during the evacuation, but in two cases, participants were temporarily separated from their children because the parents did not have a motel room or because their teenaged children were assigned to a different motel. Crowding was a problem in motel rooms, with many participants reporting that they had to sleep on the floor because spare cots were not available. Several participants experienced the inconvenience of having to relocate to a motel across the road when they were informed by motel staff that the room they had been staying in had been previously reserved after a certain date. Most participants said that there were instances of alcohol use by a small number of evacuees. Following some reported loud behavior and disturbances, Dene Tha' First Nation evacuation organizers enforced a zero-tolerance policy for disruptive behavior, which, if violated, would result in evacuees being evicted from their motel and given the option of sleeping in the reception center or in tents in Bushe River.

Problems related to preexisting health conditions were also reported by participants. Several participants forgot to bring their medications and had to wait at the hospital to get their prescriptions refilled. Many participants said they experienced difficulties breathing because of their smoke 
exposure before leaving Taché and the smoky conditions in High Level.

Most evacuees ate meals at the evacuation reception center set up at the band complex in Bushe River. Others were given vouchers for meals if their motel had an on-site restaurant. However, no money was available for evacuees to purchase other food or incidentals. A few participants who stayed in family homes or had family nearby said they had barbeques and tried to make the most of the time together. Aside from meals, some participants said they passed time by taking children swimming at motels that provided free passes. Others said they occupied their time by trying to keep informed about the evacuation and by visiting with other evacuees, which eased the stress caused by the evacuation. Daily wildfire status meetings were held in High Level and were attended by the DEM and other members of the band's leadership. Information from these meetings was subsequently passed on to evacuees during meals in Bushe River, over the band's radio station, and when volunteers periodically visited evacuees' motel rooms. However, most participants said they spent most of their time in their motel rooms and watched TV to avoid breathing the wildfire smoke outside and because they did not have anything else to do. Many participants said that they found it difficult being removed from their daily routines, and some had problems coping with the uncertainty caused by the evacuation, as explained by one participant:

All I did was I stayed there, I just felt frustrated, confused, and lost. [...] So overall that, I forget how many days we were in High Level and all I did was I just laid around and I slept. I was depressed [...] I was just too depressed [...] to go out there and socialize. So, I kind of just isolated myself [...] I just didn't want to have anything to do with it. (Participant 25)

Five days after the evacuation, the band allowed some evacuees to return home for $45 \mathrm{~min}$ to pick up personal belongings and check pets. Since the Royal Canadian Mounted Police (RCMP) had blocked the roads into the community, residents had to seek authorization at the Bushe River evacuation reception center. Bus transportation was arranged by the band for residents who wanted to return to their home but did not have a personal vehicle.

The evacuation ended on 17 July when the air quality was deemed safe enough for residents to return home. Evacuees were eligible to receive a CAD 40 purchase order (per person) at the local grocery store to replace food lost because of spoilage during the evacuation and another CAD 40 to replace gas if they had used their personal vehicle during the evacuation. This funding was provided by the band. However, not all participants were aware that they could sign up at the local store for funding to buy groceries and replace gas.

Following the evacuation, organizers and band administrators worked many hours to complete the necessary paperwork and to provide documentation so that the band could be reimbursed for expenses. When this evacuation occurred, the First Nation applied for reimbursement through the provincial government's disaster recovery program, and the provincial government applied to the federal government for reimbursement. ${ }^{1}$ It took over a year for the band to be partially reimbursed; in the interim, funds had to come out of the band's administrative budget:

[...] the funding, it takes more than a year to get. What we did with Meander was when we did our evacuation we finally, I think it took almost a year and a half to get our money back because we used the administration, the funds. And then when we get our money back the money goes back to administration. (Participant 17)

At the time of this study, participants involved in carrying out the evacuation explained that all costs of the evacuation, including accommodation, food, gas, and other essential needs, were not reimbursed with more than CAD 160,762.72 left outstanding and covered by the band.

At the time of the interviews, it was clear that a few participants were still struggling with the stress they experienced during the evacuation.

Yeah I still have effects. I feel still stressed. I never dealt with any of it [...] and there was no counsel or nothing put in place for people that would have been affected, and how it affected them and how stressful it was, and like it's just they took people and then had them go through all this stress and everything and don't even provide no counsel or nothing to help with things like that, like how it affected people. There was nothing. I don't know how they run everything. (Participant 22)

Some participants reported that certain sights and smells triggered their memories of the 2012 evacuation and made them worry about being evacuated again.

It was quite the experience but I promised myself I will not go through that again. We saw helicopters the other day and we're like oh no, we're gonna get evacuated again. Everybody's like oh no and we all start talking about it again. (Participant 6)

\footnotetext{
1 This has now changed, and First Nations in Canada now apply directly to the federal government for reimbursement under the Emergency Management Assistance Program.
} 
In contrast to this small group who reported that they continued to struggle with the evacuation 2 years afterwards, most participants said that the evacuation was an inconvenience but it did not significantly affect them over the long term.

\subsection{Factors that Helped and Hindered the Evacuation Process}

This section presents and discusses how wildfire information, community emergency preparedness, local leadership, keeping families together, and selection of host communities affected the evacuation process and impacts on evacuees.

\subsubsection{Wildfire Information}

At the beginning of a wildfire event, evacuees want realtime information on subjects such as the location, extent, and direction of the fire, the risk to homes and communities, and the possibility of evacuation (Taylor et al. 2005). In the case of the Lutose Complex fires, information about the wildfire's location and the direction of the smoke was not communicated to Dene Tha' First Nation. Even when Mackenzie County had declared a state of emergency, wildfire information and how this would affect Taché was not available through High Level's three radio stations, online newspapers, or major news networks. A similar experience of First Nations and other Indigenous communities not being adequately informed also occurred in the neighboring regional municipality of Wood Buffalo during the 2016 Fort McMurray (Horse River) wildfire (Clark 2018). Although the media was actively covering the fires near the Dene Tha' communities, their focus in the days leading up to the evacuation was on the much smaller hamlet (population 93) of Zama City. The first mention of Taché in media reports was 3 days after its evacuation. Other researchers have also found instances where the media have failed to include First Nations in their reporting (Goodchild 2003; Christianson et al. 2019) and have instead focused their coverage on the non-Indigenous communities. This lack of information meant that it was very difficult to define the risk posed to Taché, which delayed the evacuation until the late evening and overnight, which caused additional challenges. For example, one participant recalled:

We were puttin' the kids to sleep and everybody had pajamas on. And then somebody bang on my door really hard, and I was wondering what's goin' on? So, I opened the door and they said you got 15 minutes to get everything you need and to meet us at the Band office for evacuation. (Participant 13)
With little time to prepare and no specific information about the location of the wildfire, participants recalled hurriedly packing their belongings, and feeling rushed, stressed, and unprepared to spend an unknown time away from their homes. This finding is consistent with previous studies on wildfire evacuations, which have found that the amount of time between the warning and the actual evacuation significantly influences how a person copes with an evacuation (McCool et al. 2006; Stidham et al. 2011; Christianson et al. 2019).

\subsubsection{Community Emergency Preparedness}

Community preparedness includes actions taken before a hazard event to prepare for and minimize potential impacts during the response and recovery phases. In 2013, the Auditor General of Canada found that many First Nations do not have emergency plans, and of those that do have plans, many are incomplete or out of date (Office of the Auditor General of Canada 2013). Unlike many other First Nations, Dene Tha' had a general emergency plan provided by the government of Alberta that helped to guide their evacuation. The emergency plan was not tailored to Taché, however, and roles and responsibilities had not been assigned to community residents and employees before the evacuation with the exception of volunteer firefighters. Since arrangements had not been made in advance, information about the evacuation was primarily communicated by word of mouth by people who volunteered to go door to door as the events of 12 July quickly unfolded. In some cases, these volunteers did not communicate important information, such as where evacuees should go upon arrival in High Level or Bushe River. The existence of the two evacuation centers (one in the town of High Level and one in the Dene Tha' Bushe River community) combined with the lack of information to cause confusion for evacuees who went to the High Level evacuation center and were then redirected to the Bushe River evacuation center.

Another issue that arose was the sequencing of evacuees. When the initial voluntary evacuation was initiated in Taché, the fact that it only applied to community members at high risk from wildfire smoke such as elders, infants, children, and pregnant women was lost through the wordof-mouth nature in which the message spread throughout the community. As a result, many residents who did not yet need to evacuate left with their families as soon as they heard about the evacuation if they had access to transportation. Meanwhile, many residents at high risk from wildfire smoke remained in the community until bus transportation could be organized. These bus passengers were then mistakenly dropped off at the evacuation reception center in the town of High Level, rather than in the Dene Tha' organized reception center in Bushe River. 
In High Level, these evacuees did not have access to the band's evacuation organizers to arrange their accommodation. These evacuees spent the night on the floor of the reception center, which was a significant source of distress for some. As one participant explained: "I was stuck in the gym with my four kids and there were some elders in there. There were some families in there. They did not provide no blankets, nothing, just the school mats that were used to sleep on the floor there" (Participant 22). Others were more concerned with the difficulties experienced by fellow evacuees than with their own circumstances:

So, they got to town late at night and just dumped them off at the school. So, I'm not too sure if elders even had a place to stay [...], there was moms there with kids. They did not grab anything too, just got their clothes. That was it. No food, no nothing. There could have been a protocol saying that there's a fire and just be heads up that you might be evacuated or something like that would've been more helpful 'cause when I was there, the parents were there and their kids were crying, and some of them looked tired and hungry and they had nothing to eat. And some had no money so they can't get food [...]. (Participant 15)

\subsubsection{Local Leadership}

Leadership is an important factor influencing community resilience. During this evacuation, numerous decisions and logistics for the evacuation had to be rapidly carried out when the evacuation was initiated late at night under uncertain and rapidly changing conditions. The Taché evacuation was led by the volunteer DEM, with assistance from the volunteer fire chief and Dene Tha' First Nation's Chief and Council. This local leadership group quickly mobilized resources such as the local charter bus service and volunteers to go door to door to notify residents of the evacuation, set up the reception center in Bushe River, registered incoming evacuees, organized accommodation, and provided transportation from High Level motels to Bushe River for meals. Having a band-operated reception center helped develop the capacity of band employees and volunteers because they became familiar with the operation and logistics of an evacuation. In Taché, the DEM also acted as a liaison between the First Nation and government and nongovernment organizations involved in the evacuation. For example, the DEM attended daily information briefings and relayed the information to evacuees. The community action and self-organizing initiated by local leadership cultivated a sense of agency among band employees and volunteers, which has been identified in previous studies as an integral factor contributing to community resilience building (Goldstein 2008; Magis 2010; Brown and Westaway 2011; Wilson 2012).

The security of homes and pets left behind was a major concern for some participants. In response, the volunteer fire chief and a band employee remained in the community to feed pets, to provide security, to turn off natural gas to homes, and to block road access into the reserve. Together, they also provided information on local conditions to evacuees by communicating through text messages, social media, and the local radio station. As mentioned above, this helped to provide evacuees with up-to-date and locally accurate information. Local leadership also demonstrated adaptive resilience when community members were permitted to briefly return to their houses during the evacuation. This arrangement enabled community members to save money during the evacuation, eased their worries regarding the safety and security of their homes and pets, and allowed some evacuees to retain some sense of agency:

We came home one time "cause we needed some clothes, they allow us to come over, they said for an hour, like there was cops on the road, they said they give us just 45 minutes to get what we need. I did not wanna buy more clothes. (Participant 13)

It is unusual to allow evacuees to return to their homes during a mandatory evacuation because of safety concerns. Previous research has found that when residents are denied reentry to their homes and communities this decision is often a source of conflict and has even motivated some evacuees to resist evacuation in future wildfires (Kent et al. 2003; Carroll et al. 2006). However, the risks posed by smoke levels and the proximity of the wildfire were deemed low enough by the First Nation and other agencies to allow small numbers of evacuees to return home for $45 \mathrm{~min}$.

\subsubsection{Keeping Families Together}

Social support is another factor that influences community resilience. Other researchers have found that having strong social support networks helps evacuees cope with evacuations (Goodchild 2003; Carroll and Cohn 2007; Heppenstall et al. 2013; Townshend et al. 2014; Clark 2018; Asfaw et al. 2019; Christianson and McGee 2019). Previous studies have identified separation of Indigenous families during wildfire evacuations as causing additional trauma during an already stressful experience (Scharbach and Waldram 2016; Asfaw et al. 2019). In contrast, during the evacuation of Taché, evacuees received social support from family networks when they were evacuated to a Dene Tha' community (Bushe River) or the town of High Level and could stay with family; when families evacuated together; and in other ways. Extended family provided tangible 
support when they welcomed evacuees into their homes (if they resided in High Level or Bushe River), which meant that these evacuees did not need to stay in a motel or evacuation center. Several participants expressed gratitude that they could stay with family: "So I was quite thankful to stay at my brother-in-law's where I didn't have anything to worry about" (Participant 20). Previous research has found that evacuees experience a sense of insecurity in evacuation centers (Taylor et al. 2005), so the ability to stay with family helped some participants avoid a potentially distressing experience. The spread of information regarding the evacuation and the wildfires from younger family members to older family members was also a form of tangible social support identified by participants. Other ways that extended family members provided support included providing transportation, allowing evacuees to prepare meals and do laundry at their homes, and taking care of evacuees' children. This helped create a sense of order and hospitality in an otherwise disruptive situation.

Participants also received other types of support from family including positive interactions and emotional support. For example, extended family members provided support by visiting with evacuees: "Well there was a lot of people from Bushe that come visit us and either that or they'd drive us around. Walked to the hospital once in a while just to go visit patients" (Participant 26). Participants also mentioned that most families were kept together in the same motel rooms or motels and were therefore able to socialize and to support one another.

The important role of family support in participants' evacuation experience is not surprising given the importance of family in Dene Tha' First Nation, with most band members growing up in multi-generational family clusters and with extended family members contributing to different aspects of learning and support in each other's lives (Spyce 2009). By keeping families together during the evacuation, organizers were able to facilitate the tangible and emotional support provided by family. Much of this social support was also facilitated when extended family were living in High Level.

\subsubsection{Selection of Host Communities}

The selection of host communities is an important decision when a community is evacuated due to a wildfire or wildfire smoke. Place attachment describes the bonds that people develop with places (Altman and Low 1992), which provide individuals with stability, familiarity, security, predictability, and a sense of control (Brown and Perkins 1992). While other researchers have found that a wildfire evacuation can disrupt place attachment (Epp et al. 1998; Scharbach 2014; Asfaw et al. 2019), this did not occur in this case. Instead of being evacuated a long distance away and to an unfamiliar place, evacuation to the Dene Tha' Bushe River community and nearby town of High Level reduced the disruption to place attachment for Taché evacuees, because they regularly visit High Level and Bushe River to purchase groceries, access services, and visit family. Thus, when participants were evacuated to these communities, they were already familiar with the physical setting, the activities that occur there, and human social and psychological processes (meanings and attachments) that are rooted in that setting (Brandenburg and Carroll 1995). Previous research has found that success in the adjustment of evacuees to new places is a major challenge because of cultural differences between the receiving communities and evacuees (Epp et al. 1998; Goodchild 2003; Scharbach 2014). Using the band complex in Bushe River as the evacuation reception center also reduced the amount of disruption because evacuees could communicate in Dene Dháh, were familiar with local volunteers, and could eat culturally familiar meals.

While the evacuation of Taché residents to High Level and Bushe River removed them from the heavy smoke that prompted the evacuation, participants perceived that air quality in High Level still posed a significant health risk. Some participants explained that they experienced difficulties breathing because of their exposure to the smoke before leaving Taché and the sustained, though less severe, smoke conditions in High Level and Bushe River.

But I ended up with a severe asthma attack and I had to stay in the hospital all that next day on the Ventolin and the whatnots and the oxygen, and my grandson is just a little guy and he had to have Ventolin and stuff too. He's never had problems with his lungs before. But I found that in the last 2 years my breathing problems have worsened. (Participant7)

The uncomfortably hot summer weather added to this problem because most of the motels in High Level did not have air conditioning and the smoke levels prohibited the opening of windows. The band distributed water to motel rooms, but many participants recalled being very hot and uncomfortable during their stay in High Level. Participants also said that being confined to their motel rooms caused boredom and challenges entertaining children:

My kids were stressed. They had no place to play around. [...] They had no place to play. [...] And then the kids are running around outside in the parking because they needed to tire themselves out. To go to the park with them it was not good for me because I had asthma. The smoke was thick and I was going through a lot of stress and I just wanted to go home. (Participant 22) 
Dodd et al. (2018) also found that First Nation residents in the Northwest Territories, who were confined to their homes during a summer with high levels of wildfire smoke, suffered similar emotional and physical complications to those experienced by many of the Dene Tha'.

Previous research has provided clear evidence that wildfire smoke exacerbates chronic lung disease (Henderson and Johnston 2012; Reid et al. 2016; Cascio 2018) and that the prescription and use of asthma rescue medications rises rapidly during wildfire smoke events (Elliott et al. 2012). Likewise, emergency room visits and hospital admissions for respiratory illnesses also increase during the days and weeks following a wildfire event (Cascio 2018). Given that First Nations in general, and children in particular, are disproportionately affected by respiratory infections, such as viral bronchiolitis, pneumonia, and tuberculosis (Kovesi 2012), exposure to wildfire smoke may be a particularly significant health concern for First Nations. The finding from this study that wildfire smoke negatively influenced evacuation experiences indicates that smoke exposure may have undermined the benefits of using a familiar host community for some participants.

\section{Conclusion}

The results of this study contribute to a small but growing literature about the resilience of Indigenous communities during wildfire evacuations (Clark 2018; Asfaw et al. 2019; Yumagulova et al. 2019). In this case, the evacuation was hindered due to the lack of information about the nearby wildfire, smoke, and evacuation of the nearby small community of Zama City, combined with a generic evacuation plan that was not tailored to the community, which delayed and posed challenges during the evacuation of this Dene Tha' community. Although this evacuation occurred in 2012, evidence from the Horse River (Fort McMurray) fire in 2016 (Clark 2018) indicates that these communication challenges with First Nations have continued. During the 2011 evacuation of Taché, factors that helped the evacuation and influenced resilience at the community level included strong leadership and its role in community organizing, keeping families together and the social support they provided, and using familiar host communities to reduce disruption. These factors demonstrated and contributed to the community's resilience during the evacuation. Keeping families together in any wildfire evacuation is important, and particularly so in First Nation communities because extended families provide important sources of support and well-being to Indigenous residents (Kirmayer et al. 2009; Tousignant and Sioui Tousignant and Sioui 2009).
To the best of our knowledge, this is the first study to examine factors that contribute to a First Nation's decision about whether and when to call for an evacuation because of wildfire smoke. These factors include a limited wildfire and smoke information and a perception that any wildfire smoke poses a threat to health. For example, Dene Tha' First Nation evacuation organizers had to base their evacuation decision making on limited information about the fire's location and visual observations of the air quality, as there were no air quality monitors in the community. The results of this study provide context for how different levels of personal and community preparedness impact First Nation band members. For instance, in the absence of a tailored evacuation plan for Taché, the First Nation had not assigned roles and responsibilities to local health care workers. Had these local employees been included in the evacuation response, they could have helped identify residents with medical problems to prioritize their early evacuation.

Our findings have important implications for wildfire and emergency managers responsible for carrying out or supporting wildfire evacuations of First Nations in Canada. It is crucial to ensure that First Nations receive information about nearby wildfires and wildfire smoke events to assist with wildfire evacuation decision making. First Nations and other Indigenous communities should be invited to participate in emergency management activities within nearby and surrounding municipalities. Relationships between First Nations and provincial emergency management agencies should also be strengthened to ensure information is provided to First Nations without delay. Emergency preparedness plans prepared for and by communities need to be tailored to the community (also Asfaw et al. 2018; Clark 2018). Such plans should include how information will be communicated and how current evacuation procedures will work to ensure that everyone is reached and receive consistent instructions. The results of this study highlight the importance of emergency management leaders in First Nations who often carry out their roles on a voluntary basis in addition to a full-time job. Opportunities to expand DEM positions and ensure they are well supported should be examined. Whenever possible, evacuations should be made to nearby communities if the air quality does not pose a high risk to health. When heavy wildfire smoke is present, residents with preexisting respiratory conditions should be evacuated early with provisions made to ensure exposure to smoke in host communities is minimized. This could include evacuating these individuals and their families to host communities with better air quality or, as a last resort, assigning them to motels with air purifiers or air conditioning.

After this study was completed, Dene Tha' First Nation has improved their preparedness. They have carried out 
evacuation drills in collaboration with the government of Alberta's Emergency Management Agency to develop and practice their emergency plan and improve communications. In addition, Dene Tha' First Nation expanded their emergency management team to include three deputy emergency managers, with one dedicated to each of their three main communities, after the first author presented her research findings and recommendations to the First Nation in 2017.

Acknowledgements The authors would like to acknowledge the support received from Chief and Council and administration of Dene Tha' First Nation in carrying out this research. In particular, we would like to acknowledge the assistance received from Chief James Ahnassay, Sidney Chambaud, Linda Semansha and research assistants Tina Yakinneah and Cameron Chalifoux for their time, support and helpful advice. We acknowledge the members of Dene Tha' First Nation who shared their experiences during interviews. This research was made possible through funding received from the Social Sciences and Humanities Research Council of Canada in the form of the Joseph-Armand Bombardier Canada Graduate Scholarship and a Partnership Development Grant. Other grants and scholarship support included the Queen Elizabeth II Graduate Scholarship, the Walter H. Johns Graduate Scholarship, the Alberta Graduate Student Scholarship, the Northern Scientific Training Program Grant, the Canadian Circumpolar Institute CBAR Grant, and the Eugene Brody Graduate Scholarship.

Open Access This article is licensed under a Creative Commons Attribution 4.0 International License, which permits use, sharing, adaptation, distribution and reproduction in any medium or format, as long as you give appropriate credit to the original author(s) and the source, provide a link to the Creative Commons licence, and indicate if changes were made. The images or other third party material in this article are included in the article's Creative Commons licence, unless indicated otherwise in a credit line to the material. If material is not included in the article's Creative Commons licence and your intended use is not permitted by statutory regulation or exceeds the permitted use, you will need to obtain permission directly from the copyright holder. To view a copy of this licence, visit http://creativecommons. org/licenses/by/4.0/.

\section{References}

Asfaw, H.W., Sandy Lake First Nation, T.K. McGee, and A.C. Christianson. 2018. Evacuation preparedness and the challenges of emergency evacuation in Indigenous communities in Canada: The case of Sandy Lake First Nation, Northern Ontario. International Journal of Disaster Risk Reduction 34: 55-63.

Asfaw, H.W., T. McGee, and A.C. Christianson. 2019. The role of social support and place attachment during hazard evacuation: The case of Sandy Lake First Nation, Canada. Environmental Hazards 18(4): 361-381.

Alfred, T. 2009. Colonialism and state dependency. Journal de la Santé Autochtone 5(2): 42-60.

Altman, I., and S.M. Low. 1992. Place attachment: A conceptual inquiry. New York, NY: Plenum Press.

Baxter, J., and J. Eyles. 1997. Evaluating qualitative research in social geography: Establishing 'rigour' in interview analysis. Transactions of the Institute of British Geographers 22(4): 505-525.

Berkes, F., and H. Ross. 2013. Community resilience: Toward an integrated approach. Society \& Natural Resources 26(1): 5-20.
Beverly, J.L., and P. Bothwell. 2011. Wildfire evacuations in Canada 1980-2007. Natural Hazards 59(1): 571-596.

Bradshaw, M., and E. Stratford. 2010. Qualitative research design and rigour. In Qualitative research methods in human geography, 3rd edn, ed. I. Hay, 69-80. Don Mills, Ontario: Oxford University Press.

Brandenburg, A.M., and M.S. Carroll. 1995. Your place or mine? The effect of place creation on environmental values and landscape meanings. Society and Natural Resources 8(5): 381-398.

Brown, B., and D. Perkins. 1992. Disruptions in place attachment. In Place attachment, ed. I. Altman, and S. Low, 279-301. New York, NY: Plenum Press.

Brown, K., and E. Westaway. 2011. Agency, capacity, and resilience to environmental change: Lessons from human development, well-being, and disasters. Annual Review of Environment and Resources 36(1): 321-342.

Buckle, P., G. Mars, and S. Smale. 2000. New approaches to assessing vulnerability and resilience. Australian Journal of Emergency Management 15(2): 8-14.

Campbell, T.A., and Arctic Institute of North America. 1997. Dene Thá: Traditional land-use and occupancy study. Calgary, Alberta: Arctic Institute of North America.

Carroll, M.S., and P.J. Cohn. 2007. Community impacts of large wildland fire events: Consequences of actions during the fire. In People, fire and forests: A synthesis of wildfire social science, ed. T.C. Daniel, M.S. Carroll, C. Moseley, and C. Raish, 104-123. Corvallis, OR: Oregon State University Press.

Carroll, M.S., L.L. Higgins, P.J. Cohn, and J. Burchfield. 2006. Community wildfire events as a source of social conflict. Rural Sociology 71(2): 261-280.

Cascio, W.E. 2018. Wildland fire smoke and human health. Science of the Total Environment 624: 586-595.

Christianson, A.C., T.K. McGee, and Whitefish Lake First Nation. 2019. Wildfire evacuation experiences of band members of Whitefish Lake First Nation 459, Alberta, Canada. Natural Hazards 98(1): 9-29.

Clark, T.D. 2018. Rebuilding resilient indigenous communities in the RMWB: Final report. Willow Springs Strategic Solutions. http:// atcfn.ca/wp-content/uploads/2018/11/Rebuilding-Resilient-Indi genous-Communities-Final-Report-Final-1.pdf. Accessed 17 May 2020.

Cohn, P.J., M.S. Carroll, and Y. Kumagai. 2006. Evacuation behavior during wildfires: Results of three case studies. Western Journal of Applied Forestry 21(1): 39-48.

Coulthard, G.S. 2014. Red skin, white masks: Rejecting the colonial politics of recognition. Minneapolis, MN: University of Minnesota Press.

Cox, R.S., and K.-M.E. Perry. 2011. Like a fish out of water: Reconsidering disaster recovery and the role of place and social capital in community disaster resilience. American Journal of Community Psychology 48(3-4): 395-411.

Cutter, S.L., L. Barnes, M. Berry, C. Burton, E. Evans, E. Tate, and J. Webb. 2008. A place-based model for understanding community resilience to natural disasters. Global Environmental Change 18(4): 598-606.

Davidson, D.J. 2010. The applicability of the concept of resilience to social systems: Some sources of optimism and nagging doubts. Society \& Natural Resources 23(12): 1135-1149.

Dodd, W., P. Scott, C. Howard, C. Scott, C. Rose, A. Cunsolo, and J. Orbinski. 2018. Lived experience of a record wildfire season in the Northwest Territories, Canada. Canadian Journal of Public Health 109(3): 327-337.

Elliott, C.T., S.B. Henderson, and T. Kosatsky. 2012. Health impacts of wildfires: Improving science and informing timely, effective emergency response. British Columbia Medical Journal 54(10): 498-499. 
Epp, D., C.E. Haque, B. Peers, and R.C. Annis. 1998. Emergency preparedness and First Nation communities in Manitoba. Ottawa, Ontario: Emergency Preparedness Canada. http://www. publications.gc.ca/collections/Collection/D82-52-1998E.pdf. Accessed 17 May 2020.

Furgal, C., and J. Seguin. 2006. Climate change, health, and vulnerability in Canadian northern Aboriginal communities. Environmental Health Perspectives 114(12): 1964-1970.

Goldstein, B.E. 2008. Skunkworks in the embers of the Cedar Fire: Enhancing resilience in the aftermath of disaster. Human Ecology 36(1): 15-28.

Goodchild, M. 2003. The impact of culture and social inequality on risk communication: A case study of the Roseau River Anishinabe First Nation, southern Manitoba. Master thesis. Lakehead University, Canada.

Goulet, J.G. 1998. Ways of knowing: Experience, knowledge, and power among the Dene Tha. Lincoln, NE: University of Nebraska Press.

Government of Canada. 2014. TCPS2. Tri-council policy statement: Ethical conduct for research involving humans. Ottawa, Ontario: Secretariat on Responsible Conduct of Research. http://www.pre. ethics.gc.ca/eng/policy-politique/initiatives/tcps2-eptc2/Default/. Accessed 17 May 2020.

Henderson, S.B., and F.H. Johnston. 2012. Measures of forest fire smoke exposure and their associations with respiratory health outcomes. Current Opinion in Allergy and Clinical Immunology 12(3): 221-227.

Heppenstall, C.P., T.J. Wilkinson, H.C. Hanger, M.R. Dhanak, and S. Keeling. 2013. Impacts of the emergency mass evacuation of the elderly from residential care facilities after the 2011 Christchurch earthquake. Disaster Medicine and Public Health Preparedness 7(4): 419-423.

Hodgson, R. 2007. Emotions and sense making in disturbance: Community adaptation to dangerous environments. Human Ecology Review 14(2): 233-242.

Howitt, R., and S. Stevens. 2010. Cross-cultural research: Ethics, methods, and relationships. In Qualitative research methods in human geography, 3rd edn., ed. I. Hay, 30-50. Don Mills, Ontario: Oxford University Press.

Howitt, R., O. Havnen, and S. Veland. 2012. Natural and unnatural disasters: Responding with respect for Indigenous rights and knowledges. Geographical Research 50(1): 47-59.

Indigenous and Northern Affairs Canada. 2019a. First Nation Profiles. Dene Tha'. Population characteristics. https://fnp-ppn.aadncaandc.gc.ca/fnp/Main/Search/FNPopulation.aspx?BAND_NUM $\mathrm{BER}=448 \&$ lang=eng. Accessed 17 May 2020.

Indigenous and Northern Affairs Canada. 2019b. First Nation Profiles. Dene Tha'. Income characteristics. https://fnp-ppn.aadnc-aandc. gc.ca/fnp/Main/Search/FNIncome.aspx?BAND_NUMBER= 448\&lang=eng. Accessed 17 May 2020.

Indigenous and Northern Affairs Canada. 2019c. First Nation Profiles. Dene Tha'. Workforce characteristics. https://fnp-ppn.aadncaandc.gc.ca/fnp/Main/Search/FNWorkforce.aspx?BAND_NUM $\mathrm{BER}=448$ \&lang=eng. Accessed 17 May 2020.

Kent, B., K. Gerbert, S. McCaffrey, W. Martin, D. Calkin, E. Schuster, I. Martin, et al. 2003. Social and economic issues of the Hayman Fire case study. In Hayman fire case study, Gen. Tech. Rep. RMRS-GTR-114, ed. R.T. Graham, 315-396. Ogden, UT: US Department of Agriculture, Forest Service, Rocky Mountain Research Station.

Kirmayer, L.J., M. Sehdey, R. Whitley, S. Dandeneau, and C. Isaac. 2009. Community resilience: Models, metaphors and measures. Journal of Aboriginal Health 5(1): 62-117.

Kovesi, T. 2012. Respiratory disease in Canadian First Nations and Inuit children. Paediatrics and Child Health 17(7): 376-380.
Krishnaswamy, A., E. Simmons, and L. Joseph. 2012. Increasing the resilience of British Columbia's rural communities to natural disturbances and climate change. Journal of Ecosystems and Management 13(1): 1-15.

Kulig, J., A. Botey, I. Townshend, O. Awosoga, B. Shepard, D. Edge, W. Reimer, and N. Lightfoot. 2012. Families and children: Responses to wildfires-Links to community resiliency. Lethbridge, Alberta: University of Lethbridge. https://policywise. com/wp-content/uploads/resources/2016/07/FinalReport11SM KuligSept42012pdf.pdf. Accessed 14 May 2020.

Kulig, J., D. Edge, and B. Joyce. 2008. Understanding community resiliency in rural communities through multimethod research. Journal of Rural and Community Development 3(3): 77-94.

Kulig, J., W. Reimer, I. Townshend, D. Edge, and N. Lightfoot. 2011. Understanding links between wildfires and community resiliency: Lessons learned for disaster preparation and mitigation. Boulder, CO: Natural Hazards Center. http://www.ruralwildfire. $\mathrm{ca} /$ sites/ruralwildfire/files/Barriere, \%20BC,\%20and\%20La\% 20Ronge, $\% 20$ SK $\% 20-\% 20$ Final\%20Report $\% 202011$.pdf. Accessed 14 May 2020.

LaFromboise, T.D., D.R. Hoyt, L. Oliver, and L.B. Whitbeck. 2006. Family, community, and school influences on resilience among American Indian adolescents in the upper midwest. Journal of Community Psychology 34(2): 193-209.

Levy, D., H. Itzhaky, L. Zanbar, and C. Schwartz. 2012. Sense of cohesion among community activists engaging in volunteer activity. Journal of Community Psychology 40(6): 735-746.

Magis, K. 2010. Community resilience: An indicator of social sustainability. Society and Natural Resources 23(5): 401-416.

Manyena, S.B. 2006. The concept of resilience revisited. Disasters 30(4): 434-450.

McCool, S.F., J.A. Burchfield, D.R. Williams, and M.S. Carroll. 2006. An event-based approach for examining the effects of wildland fire decisions on communities. Environmental Management 37(4): 437-450.

McGee, T.K. 2019. Preparedness and experiences of evacuees from the 2016 Fort McMurray Horse River wildfire. Fire 2(1): Article 13.

McGee, T.K., Mishkeegogamang Ojibway Nation, and A.C. Christianson. 2019. Residents' wildfire evacuation actions in Mishkeegogamang Ojibway Nation, Ontario, Canada. International Journal of Disaster Risk Reduction 33: 266-274.

Office of the Auditor General of Canada. 2013. Emergency management on reserves. In Report of the Auditor General of Canada. http://www.oag-bvg.gc.ca/internet/English/parl_oag_201311_ 06_e_38800.html. Accessed 17 May 2020.

Paton, D., L. Smith, and J. Violanti. 2000. Disaster response: Risk, vulnerability and resilience. Disaster Prevention and Management: An International Journal 9(3): 173-180.

Paveglio, T.B., M.S. Carroll, and P.J. Jakes. 2008. Alternatives to evacuation - Protecting public safety during wildland fire. Journal of Forestry 106(2): 65-70.

Reid, C.E., M. Brauer, F.H. Johnston, M. Jerrett, J.R. Balmes, and C.T. Elliott. 2016. Critical review of health impacts of wildfire smoke exposure. Environmental Health Perspectives 124(9): 1334-1343.

Scharbach, J. 2014. The sociocultural implications of emergency evacuation among members of the Hatchet Lake First Nation. Master thesis. University of Saskatchewan, Saskatoon, Canada.

Scharbach, J., and J.B.Waldram. 2016. Asking for a disaster: Being 'at risk' in the emergency evacuation of a Northern Canadian Aboriginal Community. Human Organization 75(1): 59-70.

Spyce, T.M. 2009. Disruption in place attachment: Insights of young Aboriginal adults on the social and cultural impacts of industrial development in Northern Alberta. M.Sc. thesis, University of Alberta, Edmonton, Canada. 
Stidham, M., E. Toman, S. McCaffrey, and B. Shindler. 2011. Improving an inherently stressful situation: The role of communication during wildfire evacuations. In Proceedings of the second conference on the human dimensions of wildfire, ed. S. McCaffrey, and C. Fisher, 96-103. Newtown Square, PA: USDA Forest Service, Northern Research Station.

Tally, S., A. Levack, A.J. Sarkin, T. Gilmer, and E.J. Groessl. 2012. The impact of the San Diego wildfires on a general mental health population residing in evacuation areas. Administration and Policy in Mental Health and Mental Health Services Research 40(5): 348-354.

Taylor, J.G., S.C. Gillette, R.W. Hodgson, and J.L. Downing. 2005. Communicating with wildland interface communities during wildfire. Reston, VA: US Department of the Interior, US Geological Survey. https://www.fort.usgs.gov/sites/default/files/ products/publications/21411/21411.pdf. Accessed 17 May 2020.

Tierney, K., and M. Bruneau. 2007. Conceptualizing and measuring resilience: A key to disaster loss reduction. TR News 250: 14-15, 17.

Tousignant, M., and N. Sioui. 2009. Resilience and Aboriginal communities in crises: Theories and interventions. Journal of Aboriginal Health 5(2): 43-61.
Townshend, I., O. Awosoga, J. Kulig, and H. Fan. 2014. Social cohesion and resilience across communities that have experienced a disaster. Natural Hazards 76(2): 913-938.

Twigg, J. 2009. Characteristics of a disaster-resilient community: A guidance note (Report). Teddington, UK: DFID Disaster Risk Reduction NGO Interagency Group. http://discovery.ucl.ac.uk/ 1346086/. Accessed 17 May 2020.

Wilson, G. 2012. Community resilience and environmental transitions. New York, NY: Routledge.

Wotton, B.M., and B.J. Stocks. 2006. Fire management in Canada: Vulnerability and risk trends. In Canadian wildland fire strategy: Background syntheses, analyses, and perspectives, ed. K.G. Hirsch, P.L. Fuglem, and Canadian Council of Forest Ministers, 49-55. Edmonton, Alberta: Canadian Council of Forest Ministers.

Yumagulova, L., S. Phibbs, C.M. Kenney, D.Y. Old Woman-Munro, A.C. Christianson, T.K. McGee, and R. Whitehair. 2019. The role of disaster volunteering in Indigenous communities. Environmental Hazards. https://doi.org/10.1080/17477891.2019. 1657791. 